\title{
Um Ambiente para Autoria e Realização de Aventuras Pedagógicas Digitais
}

\author{
Douglas Alves do Espírito Santo ${ }^{1}$ Crediné da Silva Menezes ${ }^{1,2}$ \\ ${ }^{1}$ Programa de Pós-graduação em Informática - Universidade Federal do Espírito Santo \\ (UFES) \\ Av. Fernando Ferrari, 514, Goiabeiras, -29.075-910 - Vitória - ES - Brazil \\ ${ }^{2}$ Faculdade de Educação - Universidade Federal do Rio Grande do Sul (UFRGS) \\ Caixa Postal 15.064 - 91.501-970 - Porto Alegre - RS - Brazil \\ daesmestrado@gmail.com, credine@gmail.com
}

\begin{abstract}
The new scenario offered by digital technologies favors distance activities and active learning practices within the cooperative paradigm. A major obstacle to be overcome is the unavailability of methodologies and technologies for teachers and students to build new cognitive ecosystems. Seeking to offer alternatives we have designed an environment for creation and realization of educational adventures, which are learning situations inspired by the elements of RPG games. The main features of the environment include: a) the persistence of virtual items, conquered by an adventurer, that enable the integration between different adventures and, $b$ ) the integration of the adventures carried out with other communication mechanisms present in digital culture.
\end{abstract}

Keywords - Educational Architecture, Digital Games, Environment for building games, Pedagogical Adventures.

Resumo. O novo cenário oferecido pelas tecnologias digitais favorece a realização de atividades à distância e a adoção de práticas pedagógicas ativas, dentro do paradigma cooperativo. Um grande obstáculo a ser superado é a indisponibilidade de metodologias e tecnologias para que professores e alunos construam novos ecossistemas cognitivos. Buscando oferecer alternativas concebemos um ambiente para a criação e realização de aventuras pedagógicas, que se constituem em situações de aprendizagem inspiradas nos elementos de jogos do tipo RPG. Entre as principais características do ambiente destacam-se: a) a persistência dos itens virtuais, conquistados por um aventureiro, que possibilitam a integração entre diferentes aventuras $e$, b) a integração das aventuras realizadas com outros mecanismos de comunicação presentes na cultura digital.

Palavras-chave - Arquitetura pedagógica, Jogos Digitais, Ambiente para construção de jogos, Aventuras Pedagógicas.

\section{Introdução}

Segundo Carvalho, Nevado e Menezes (2005) as arquiteturas as arquiteturas pedagógicas são estruturas de aprendizagem realizadas a partir da confluência de diferentes perspectivas: abordagem pedagógica, software, internet, inteligência artificial, educação a distância e concepção de tempo e espaço. Nesse contexto estão os 
jogos digitais, que podem ser elaborados de forma a reunir elementos que os tornem propícios a um aprendizado mais dinâmico e flexível, podendo serem levados para além da sala de aula e da escola tradicional. Dentre os gêneros de jogos digitais mais propícios à educação estão as Aventuras Pedagógicas.

Para Gee (2005) bons videogames (idem aos bons jogos de computadores, inclusas as aventuras pedagógicas) incorporam bons princípios de aprendizagem, apoiados em pesquisas em Ciência Cognitiva. Prensky (2012) destaca ser a diversão proporcionada pelos jogos o principal elemento que os tornam eficientes no processo de ensino e aprendizagem. Para o autor, a diversão é eficiente pois motiva e relaxa. Mark Griffiths (2002) descreve que os jogos digitais podem ajudar no desenvolvimento de competências entre grupos de necessidades especiais; também, o biofeedback de ondas cerebrais ensinam crianças com déficit de atenção e hiperatividade a controlar funções involuntárias do corpo como frequência cardíaca, melhorando também o grau de sociabilidade e a capacidade de organização.

Para que os professores possam fazer uso desse tipo de arquitetura pedagógica, necessitam antes criá-las adequando-as aos assuntos relacionados as suas disciplinas, ou melhor ainda, trabalhando em grupo de forma interdisciplinar. Entretanto, esses profissionais não são, em sua maioria, capacitados tecnicamente para construção de jogos, tarefa essa um tanto complexa, que exige conhecimentos no campo das ciências da computação. Uma forma de possibilitar que esses profissionais construam seus próprios jogos é oferecer-lhes um ambiente de desenvolvimento, de fácil utilização, que não requeira conhecimentos de linguagens de programação de computadores.

Neste contexto, concebemos e estamos na fase final de desenvolvimento do CAPeD, (um Ambiente de desenvolvimento integrado), que possibilita a construção de aventuras pedagógicas, baseadas em jogos digitais online, por usuários sem conhecimento de programação, entre os quais podemos considerar os alunos e professores, em diversos níveis escolares. Este está organizado em 7 seções. Na primeira seção, foi feita a introdução do trabalho. Na segunda seção são apresentados os objetivos da pesquisa. A metodologia de pesquisa é apresentada na seção 3. A seção quatro trata dos trabalhos relacionados. As informações relativas ao projeto do Ambiente estão descritas na seção 5 e suas subseções. Na seção 6 é apresentado um exemplo de Arquitetura Pedagógica que parte de um jogo. Finalmente, na seção 7 descreve as considerações finais.

\section{Objetivo da proposta}

De forma geral, este artigo tem como objetivo principal apresentar o Construtor de Aventuras Pedagógicas Digitais (CAPeD), um Ambiente na Internet em fase final de implementação, na forma de um Ambiente de Desenvolvimento Integrado (IDE), para que professores e alunos do ensino fundamental e médio, e outros interessados que não saibam programar, possam construir e jogar jogos digitais do tipo aventuras pedagógicas.

Objetiva também, descrever e discutir a importância do ambiente como ferramenta de apoio para construção de arquitetura pedagógicas baseadas em jogos digitais; descrever elementos e características dos jogos digitais e do ambiente, que permitam concluir a necessidade de que professores e alunos se apropriem deste tipo de ferramenta para construir jogos voltados aos conteúdos das suas disciplinas. 
Discutir a possibilidade de construção de outras arquitetura pedagógicas com base no ato de criar e jogar os jogos através do CAPeD. Apresentar um jogo de Aventura Pedagógica como exemplo possível de ser criado pelo ambiente a fim de validá-lo. Apontar como objetivo posterior a importância de utilizar o CAPeD na prática, junto aos professores alunos de algumas escolas.

\section{Metodologia}

Partindo do pressuposto de que os jogos digitais são uma abordagem pedagógica eficiente e eficaz de apoio ao processo de ensino e aprendizagem, da importância da apropriação deste tipo de arquitetura pedagógica por professores e alunos, e da necessidade de desenvolvimento de uma ferramenta de suporte para a construção desse tipo de atividade, foi feito um levantamento bibliográfico do estado da arte, focando em tópicos de relevância para o projeto, tais como: mundos virtuais, jogos digitais, Motores de Jogos (Game Engines), arquitetura de Motores de Jogos, design de jogos e aprendizagem através de jogos digitais. Paralelamente foram experimentadas ferramentas de autoria para construção de jogos digitais, tanto comerciais, como com fins educativos a fim de compreender suas características e funcionalidades.

Posteriormente foi realizado um levantamento de requisitos e utilizada uma metodologia ágil na construção de um protótipo; isso implica dizer que esse protótipo está sendo desenvolvido de forma incremental. A decisão por adotar esta metodologia de desenvolvimento, se deu por ser o ambiente uma aplicação web complexa, e entregar o software em incrementos dá maior flexibilidade no desenvolvimento e teste do mesmo. Portanto, estão sendo realizados testes funcionais, durante o próprio desenvolvimento; quando necessário, são realizados testes de integração entre os módulos. Entre as ferramentas de software que estão sendo utilizados na construção do protótipo, temos as linguagens Python e Javascript, a biblioteca jQuery, a Hypertext Markup Language - Linguagem de Marcação de Hipertexto versão 5 (HTML5), a Cascading Style Sheets - Folha de Estilo em Cascata (CSS) e o framework Django. Observando que o próprio Django é um framework criado para atender a projetos de software web com prazos bem curtos.

Por fim foi concebido, apresentado e discutido o "Jogo do Supermercado", que reúne características de simulação de uma atividade da vida real, difícil de ser reproduzida em nosso mundo físico com uma turma de alunos, tendo em vista a interferência indesejável na rotina em um estabelecimento comercial além de possíveis desperdícios de produtos.

\section{Trabalhos relacionados}

O La Vouivre é um software Francês, gratuito com o qual pode-se criar Jogos de pergunta e resposta. O jogo da Glória é um dos jogos criados com o software [Carvalho 2012]. Um jogo qualquer, criado com o La Vouivre, constará de um tabuleiro cujas casas podem conter imagens representativas. $\mathrm{O}$ jogo permite até 4 jogadores. Ao iniciar o jogo, se houver mais de um jogador, o programa escolhe aleatoriamente quem inicia. O jogador lança o dado, e na visualização, um peão percorre o tabuleiro até parar numa das casas. Uma pergunta de múltipla escolha é feita ao jogador, que ao escolher uma das respostas é informado pelo programa se houve acerto ou não. É feita uma pergunta por vez a cada jogador, e o ciclo se inicia novamente. O programa permite exportar o jogo como página da $w e b$. 
V Congresso Brasileiro de Informática na Educação (CBIE 2016)

Anais dos Workshops do V Congresso Brasileiro de Informática na Educação (CBIE 2016)

O e-Adventure é uma plataforma para desenvolvimento de jogos de aventura com fins educativos. A plataforma, desenvolvida pelo grupo de pesquisa da Universidade Complutense de Madrid, possui um Motor de Jogos e o editor gráfico eAdventure. $\mathrm{O}$ editor permite a criação de jogos em primeira ou terceira pessoa sem a necessidade de conhecer programação. $O$ arquivo de projeto é salvo com a extensão "ead", podendo ser carregado mais tarde para alteração ou execução do jogo. A plataforma inclui também mecanismos de criação e avaliação de relatórios dos resultados do jogo; tais jogos podem ser exportados como objetos educacionais e integrados à plataforma de suporte de ensino on-line [Lopes e Oliveira 2013].

O Adventure Maker roda em Windows e cria jogos para Windows, PSP, iPhone, iPod Touch [Adventure Maker, 2016]. Ao criar software para Windows, por exemplo, o Adventure Maker oferece as opções de criar um novo Frame ou editar um Frame existente. Ao editar um frame, e para criar o jogo em si, é necessário inserir Hot Spots, que consistem de imagens e textos, onde podem ser inseridas ações, ao realizar o click com o mouse sobre eles. Permite ainda inserir conversas, itens de estoque, suporte para Flash, som, vídeo, entre outros.

A tabela 1 faz um comparativo entre o CAPeD e outros ambientes que facilitam a construção de jogos. Foram listadas características consideradas importantes num software utilizado para a construção de jogos educativos. Observe que o mais próximo deles é o e-Adventure, que, mesmo assim, ainda está bem distante da proposta do CAPeD.

Tabela 1 - Comparação entre Características dos Ambientes / Game Engines

\begin{tabular}{|l|c|c|c|c|c|c|}
\hline \multicolumn{1}{|c|}{ Características } & \multicolumn{5}{c|}{ AMBIENTE / GAME ENGINE } \\
\cline { 2 - 7 } & CAPeD & $\begin{array}{c}\text { La } \\
\text { Vouivre }\end{array}$ & $\begin{array}{c}\text { e- } \\
\text { Adventure }\end{array}$ & $\begin{array}{c}\text { Adventure } \\
\text { Maker }\end{array}$ & Unit 3D & Construct 2 \\
\hline Construção online de jogos & $\bullet$ & - & - & - & - & - \\
\hline $\begin{array}{l}\text { Os jogos podem ser jogados online e com diversos } \\
\text { jogadores }\end{array}$ & - & - & - & - & - & - \\
\hline É voltado à criação de aventuras pedagógicas & $\bullet$ & - & - & - & - & - \\
\hline $\begin{array}{l}\text { Permite a criação de grupos fechados para jogar um } \\
\text { determinado jogo }\end{array}$ & - & - & - & - & - & - \\
\hline $\begin{array}{l}\text { Reúne informações para que um software } \\
\text { complementar possa auxiliar na avaliação das } \\
\text { aprendizagens }\end{array}$ & - & - & - & - & - & - \\
\hline $\begin{array}{l}\text { Dispensa a instalação de qualquer parte do software, } \\
\text { plug-ins ou outros softwares na máquina do cliente }\end{array}$ & - & - & - & - & - & - \\
\hline $\begin{array}{l}\text { Permite a persistência de objetos para fora do jogo para } \\
\text { apoiar outras atividades educativas }\end{array}$ & - & - & - & - & - & - \\
\hline $\begin{array}{l}\text { Faz a persistência dos objetos dos alunos atrelando-os } \\
\text { ao seu login e permitindo utilizá-los em outras } \\
\text { aventuras. }\end{array}$ & - & - & - & - & - & - \\
\hline $\begin{array}{l}\text { Possui ou é passível de ter portal interativo para os } \\
\text { jogos e para a comunidade de usuários }\end{array}$ & - & - & - & - & - & - \\
\hline
\end{tabular}

\section{O Ambiente online para criação de jogos digitais}

Para apresentar o CAPeD serão destacadas suas características, os tipos de jogos que poderão ser construídos e jogados, os ganhos dos professores e alunos na utilização do ambiente, a arquitetura, a forma de criar e jogar os jogos e as contribuições para a educação.

\subsection{As características do Ambiente}


O ambiente proposto é uma aplicação web, que pode de forma fácil e sem custos ser apropriado por professores e alunos para a criação de Arquiteturas Pedagógicas baseadas em jogos digitais. Para usá-lo é preciso apenas de um browser e uma conexão de internet com banda larga. Tais características quebram a barreira de tempo e espaço, permitindo que a atividade educativa aconteça estando os participantes em qualquer local.

O ambiente proposto foi projetado para a criação de jogos onde vários jogadores possam jogá-los ao mesmo tempo, interagindo tanto com os personagens do jogo (NPC - Non Player Character), quanto com personagens controlados por outros jogadores humanos. Os jogos criados no ambiente ficam disponíveis num portal, e podem ser acessados e jogados por qualquer pessoa cadastrada. $\mathrm{O}$ ambiente em si possui um espaço reservado ao usuário, onde ele encontra os jogos criados e jogados por ele. $\mathrm{O}$ ambiente permite ainda a possibilidade de realização de atividades extraclasse (fora da escola), como a criação de campeonatos entre turmas de mesma escola e de diferentes escolas.

Outras mídias poderiam ser utilizadas pelos jogadores, como vídeos e fóruns, para que se integrem as outras atividades pedagógicas. Como exemplo, após participar de uma aventura, o aluno poderia publicar no portal citado as suas experiências no jogo, ou fazer perguntas relevantes sobre o mesmo num fórum no mesmo portal. Durante a jornada de um jogador num determinado jogo, os objetos por ele coletados ficam atrelados ao seu perfil permanentemente. Elementos utilizados na criação de um determinado jogo ficam disponíveis no ambiente para criação de outros, possibilitando a formação de novas Arquiteturas Pedagógicas. Ao formar a base de dados dos jogadores e das construções dos jogos, o ambiente pode disponibilizar informações para um sistema complementar, capaz de realizar a avaliação do jogador, no sentido de oferecer feedback ao mesmo sobre as questões do jogo.

\subsection{Tipos de jogos possíveis de serem criados no CAPeD e os benefícios do seu uso}

Jogos do tipo Role-Playing Games (RPG) em versão digital tiveram início em meados da década de 70 [Crawford 1984]; evoluindo para os Massively Multiplayer Online Role-Playing Games (MMORPGs) uma categoria de RPG digital que consta de um mundo virtual, onde vários jogadores podem estar conectados. Devido a essas características, esses jogos também são chamados de mundos virtuais persistentes. Dos MMORPGS surgem as Aventuras Pedagógicas. Uma aventura pedagógica consiste num mundo virtual, criado com fins educativos, onde vários participantes podem se conectar a qualquer momento, vivenciando a história do mundo, através de personagens controlados por eles próprios, resolvendo uma série de problemas e mantendo uma identidade complexa.

Nesse mundo virtual, o participante pode interagir tanto com personagens comandados por outros jogadores, como com personagens controlados pelo próprio jogo, chamados de non-player characters - personagens não jogáveis (NPCs). Por ser um mundo virtual, os jogadores não correm os riscos da vida real e sempre podem voltar ao último estado consistente do jogo, no caso de perder uma "partida". Para Bomfoco (2012), essas características tornam as Aventuras Pedagógicas, um gênero de jogo adequado ao propósitos educacionais.

Ao utilizarem o ambiente, professores e alunos são levados a construir seus conhecimentos, pois necessitam estudar o assunto do jogo a ser criado, discuti-lo com 
os colegas, usar a criatividade e adquirir manejo no uso do ambiente. As atividades não terminam com a construção dos jogos e nem mesmo com o ato de jogá-los, e o professor, atuando como mediador, pode conduzir uma rodada de debates, incentivando os alunos a descreverem suas experiências, escolhas e decisões no jogo.

Neste contexto, há a possibilidade do desenvolvimento das habilidades cognitivas e das experiências sociais e epistemológicas dos jogadores. Eles podem explorar novas identidades e realizar experimentações lúdicas. É possível levar ao desenvolvimento de uma cultura de grupo, por pessoas que agem e pensam de forma semelhante, formando uma comunidade de prática, com interesses, objetivos, habilidades e identidades parecidas. Para Santos (2011 apud Johnson e Levine 2010) a interação com diversos participantes no mesmo espaço virtual e tempo propicia a criação de amizades, comunidades e possivelmente novas sociedades e culturas.

\subsection{Projeto do Ambiente}

A arquitetura foi subdividida em subsistemas específicos a determinada atividade no jogo, como o de áudio, renderização e Inteligência Artificial; os subsistemas possuem um conjunto de classes que lhes fornecem uma interface com diversas funcionalidades. Para se ter uma visão clara dos módulos do sistema, foi utilizada a Unified Modeling Language - Linguagem de Modelagem Unificada (UML) na modelagem do software, e conforme orienta Nunes e O'Nell (2004) o projeto foi desenvolvido de forma iterativa e incremental, baseado numa arquitetura centrada em casos de uso.

Foram levantados os casos de uso, construídos os diagramas de classe e desenvolvidas as funcionalidades de forma incremental. A escolha da linguagem Python e do framework Django se deu por proporcionarem facilidade e rapidez na construção de softwares em geral. No front-end foi utilizada a linguagem JavaScript, a biblioteca jQuery, o CSS e HTML5. O Ambiente de desenvolvimento utilizado foi o Eclipse com o plug-in do PyDev, para permitir a construção de programas Python nesse ambiente.

Segundo Carmona e Carneiro (2010), uma Game Engine (ou motor de jogo) é um programa de computador (conjunto de rotinas) que visa simplificar e abstrair o desenvolvimento de jogos digitais. Ou seja, uma Game Engine, facilita a construção de jogos, pois já traz uma série de rotinas prontas que podem ser utilizadas, sem a necessidade de recodificação. A arquitetura do Ambiente, juntamente com a de sua Game Engine é apresentada na figura 01. Dentro do retângulo cinza temos o Motor de Jogos em si, o restante, está fora da fronteira do motor, mas comunica-se com ele para completar a arquitetura do Ambiente. O módulo de áudio permite a inserção e controle de sons nos jogos criados, que vão desde barulhos por colisão ou movimento, até músicas para enfatizar o enredo do jogo. O módulo de entrada/interação capta as entradas dos usuários por meio do mouse e teclado, transformando-as em ações no mundo do jogo.

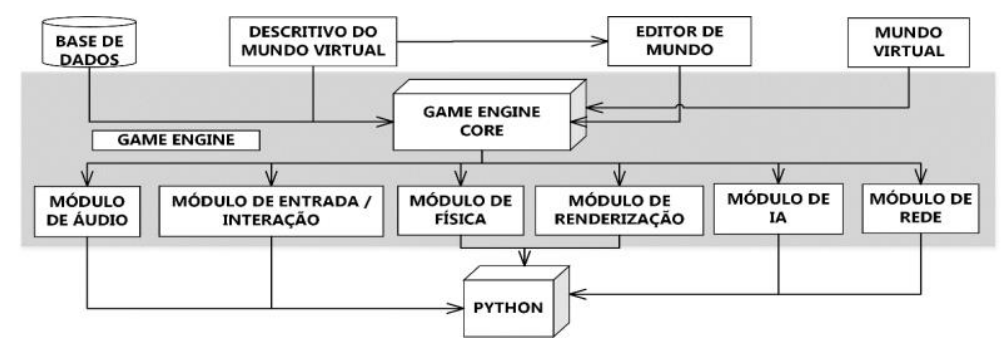

Figura 1 - A Arquitetura do Ambiente de Desenvolvimento de Jogos 
O módulo de física controla as interações ocorridas nos jogos criados, como colisões em geral; e o módulo de renderização trata da compilação gráfica dos jogos. $\mathrm{O}$ módulo de Inteligência Artificial (IA) proporciona feedback ao jogador, fazendo os NPCs responderem a perguntas ou darem respostas. O módulo de rede faz o trabalho pesado de transferência de dados entre cliente (jogador) e servidor. A Game Engine Core é um módulo coordenador, que faz a integração entre os módulos descritos e o que está fora da fronteira da Game Engine (Base de dados e editor de mundos), distribuindo as tarefas aos módulos corretos, facilitando o gerenciamento do jogo como um todo.

\subsection{Elementos oferecidos pelo Ambiente para construção de jogos}

O ambiente oferece uma interface para criar o jogo, suas fases e os cenários das fases. Imagens externas poderão ser carregadas através do ambiente para a construção dos jogos. Elas poderão representar os avatares dos NPCs, e demais elementos do jogo como obstáculos, muros, paredes, portas, janelas, buracos, entre outros. Também estarão disponíveis algumas figuras geométricas bidimensionais para inserção direta nos cenários, como: círculos, quadrados, retângulos, triângulos, entre outras. As imagens utilizados pelos usuários na construção dos jogos serão armazenadas numa base comum de onde poderão ser resgatadas para utilização em outros jogos. O CAPeD oferece suporte à organização de bibliotecas de itens, pequenas animações e imagens que serão construídas e formadas à medida que os jogos forem sendo criados.

Os personagens poderão receber habilidades, como: andar, saltar, correr, coletar e movimentar objetos, obter ferramentas e armas. Poderão também interagir com outros personagens controlados por humanos, através de diálogos digitados no teclado. Os NPCs poderão dar dicas e fazer perguntas aos jogadores, através de diálogos escritos previamente pelo construtor do mundo. Às ações e decisões dos jogadores lhes trarão feedbacks do jogo. Por exemplo, ao tocar num NPC com o click do mouse, o personagem poderá receber uma dica, ou qualquer outro tipo de informação, ou mesmo receber uma pergunta. Ao terminar uma tarefa, o jogador poderá ganhar pontos, vida, mais tempo de jogo ou dinheiro.

\subsection{Como usar o Ambiente para construir e jogar jogos}

Para poder criar jogos o usuário deverá interagir primeiro com o portal cooperativo. Esse portal deve suportar a publicação de posts, lista de jogos, fóruns, chat, notícias, entre outras possibilidades que serão amadurecidas com o decorrer do tempo. A ideia é que seja um local único de interação entre interessados em jogos digitais $\mathrm{e}$ aprendizagem. Após cadastrado e logado no portal, o usuário poderá acessar o Ambiente e iniciar a criação de um novo jogo, ou alterar um existente. A figura 02 ilustra um diagrama de comunicação para o caso de uso "CriarAventuraPedagogica".

Cria-se o jogo através da interface apropriada do ambiente, dando-lhe um título e uma descrição. Depois, para o jogo criado, deverá ser criada uma ou mais fases, lhes dando igualmente um título e uma descrição. Para cada faze poderão ser criados um ou mais cenários, atrelando-se a eles os elementos do mundo. Os elementos do mundo são os personagens, objetos e construções que o compõem. 
V Congresso Brasileiro de Informática na Educação (CBIE 2016)

Anais dos Workshops do V Congresso Brasileiro de Informática na Educação (CBIE 2016)

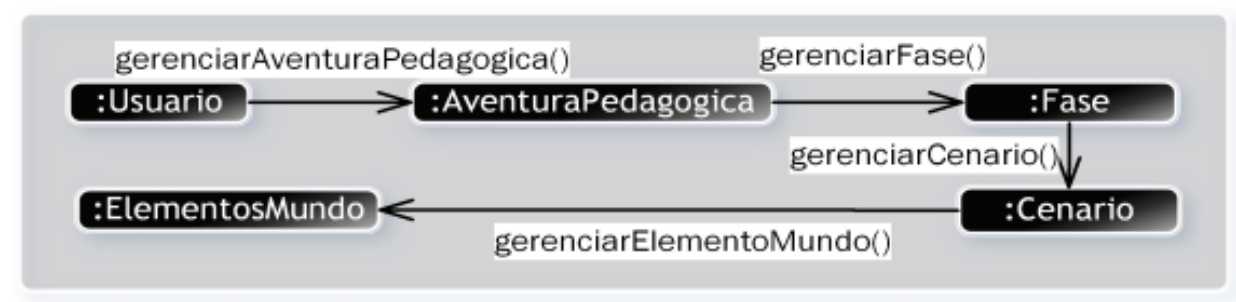

Figura 2 - Diagrama de comunicação para a criação de Aventuras Pedagógicas

Inseridos os elementos, deverão ser associados os comportamentos relativos a cada um, se houver necessidade. Um personagem, por exemplo, poderá ter a capacidade de andar, correr, coletar coisas, entre outras. Um jogo, após criado, salvo e testado, poderá ser publicado no Ambiente, ficando disponível para ser jogado. O usuário só poderá alterar um jogo de sua autoria, que ainda não foi terminado. É importante testar o jogo antes de publicá-lo.

Para jogar os jogos, após registrado no portal, um usuário deverá através do link apropriado, ser direcionado para o espaço dele no ambiente. Lá estarão os jogos criados e já jogados por ele. Nesse espaço ele poderá criar novos jogos, ou voltar a jogar um dos jogos que já iniciou. Caso queira jogar um jogo que ainda não jogou, deverá voltar ao portal e escolhe-lo na lista existente. A figura 3 ilustra um diagrama de comunicação para o caso de uso "JogarAventuraPedagogica".

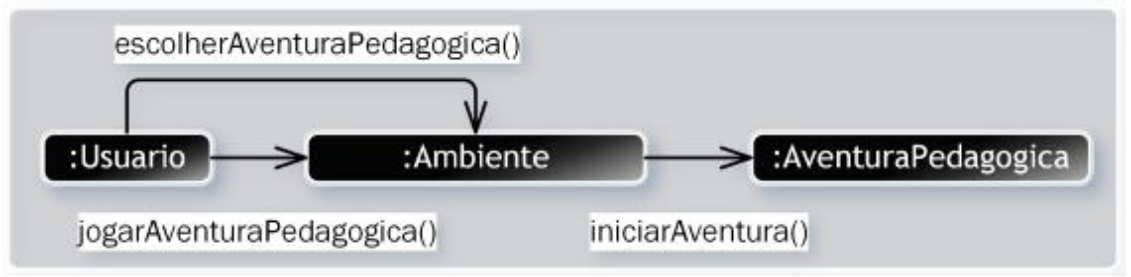

Figura 3 - Diagrama de comunicação para o caso de uso JogarAventuraPedagogica

É possível criar uma instância do jogo, e com essa instância formar um grupo fechado de jogadores, incluindo no jogo apenas as pessoas de interesse. Essa possibilidade é particularmente interessante para professores, que poderão criar instâncias dos jogos para suas turmas, de forma a promover outras arquiteturas pedagógicas com tais grupos, a partir dos jogos jogados por eles. Uma arquitetura pedagógica pós jogo, possível de ser criada, seria a reunião da turma para fazer um levantamento e registro das dúvidas dos alunos relativas ao assunto do jogo, conduzindo os mesmos a responderem essas dúvidas, e a sintetizarem as respostas para chegar a uma conclusão cooperativa.

\section{Proposta pedagógica que parte de um jogo}

Pense num docente que leciona para turmas do Ensino Fundamental I, e que queira levar seus alunos para experimentarem uma tarde de compras no supermercado. Na vida real isso seria muito difícil, tendo em vista a quantidade de alunos, pela necessidade de dinheiro, pela provável não aceitação de tal visita pelo dono do supermercado, entre outras. Assim, essa visita poderia ser simulada num jogo, onde todos os inconvenientes acima seriam eliminados. O pano de fundo do jogo pode ser a planta baixa do supermercado, onde as divisões indicariam as seções existentes. Cada seção será suprida por diferentes produtos, que podem ser configurados de diferentes formas, de acordo com algum interesse do professor. Logo de início, os jogadores receberiam um cartão 
com um valor em dinheiro para comprar. Eles percorreriam o supermercado usando as teclas de seta do teclado, visitando as diversas seções, e com cliques do mouse poderiam pesquisar o produto, consultar preços, rótulos ou colocá-los no seu carrinho de compras.

Eles poderiam também interagir com funcionários do supermercado, fazendo perguntas e recebendo respostas; poderiam interagir com outros jogadores humanos (outros alunos), discutindo as características dos produtos, seus preços, receitas que poderiam ser feitas com eles. O supermercado digital poderia ter alguns terminais de computador interligados na internet, ou mesmo com um software proprietário do estabelecimento, onde os alunos poderiam fazer pesquisas relativas aos produtos e suas substâncias. Poderiam pesquisar o que é mais ou menos saudável, de onde se originam os produtos ou como são fabricados. O portal poderia ser usado para que os alunos fizessem posts em um blog sobre suas experiências no jogo; poderiam ainda, fazer perguntas em fóruns ou direcioná-las para outro aluno ou professor.

Por fim, o aluno pagaria sua compra e a visita terminaria. Uma dinâmica posterior ao jogo, constituindo outra arquitetura pedagógica, seria realizada com a turma, em conjunto com o professor, que conduziria um debate sobre as escolhas dos alunos, os preços dos produtos, a qualidade dos mesmos, entre outras; no debate dúvidas poderiam ser levantadas, assim como possíveis respostas para as mesmas. Após entenderem melhor os produtos em relação a qualidade, preço, benefícios e malefícios, os alunos poderiam trocar os produtos entre si, ou mesmo vendê-los ou comprá-los uns dos outros.

Outro exemplo, seria uma aventura que leva-se os alunos a um passeio pela idade média. O objetivo poderia ser familiarizá-los com a cultura e a forma de vida da época. O jogador recebendo inicialmente uma quantidade de terras, um valor em dinheiro e uma quantidade de mantimentos, seria incentivado a melhorar sua posição social. Para isso, teria que construir seu próprio feudo, trazendo trabalhadores e profissionais autônomos como clérigos, médicos, engenheiros construtores, dentre outros; interagiria com personagens que pudessem ajudá-lo, em troco de dinheiro ou algum outro benefício; visitaria feudos vizinhos e a cidade onde estaria situado o palácio do rei; compraria e venderia alimentos e objetos de uso da época. Uma aventura como essa se constituiria num minimundo, criado pelo professor, para atender a algum requisitos de aprendizagem.

\section{Considerações finais}

Tendo em vista os recursos de comunicação disponibilizado pela tecnologia digital, estamos vivenciando o início de uma revolução na forma de criar novas ecologias cognitivas baseadas na revisão dos conceitos do espaço e tempo, que por muito engessaram a concepção de novas práticas pedagógicas. Para vencer esta barreira precisamos de novas ferramentas conceituais e tecnológicas para construção de novos ecossistemas. Neste artigo, apresentamos uma proposta baseada em Aventuras Pedagógicas e um ambiente para que professores e alunos possam construí-las e vivencia-las. Os jogos criados através desse ambiente possuem certas características agregadas, as quais os tornam mais completos para uso educacional; ente elas está a possibilidade de serem jogados online, permitirem a coleta e armazenamento dos objetos do mundo, de tirar fotos e fazer filmagens. 
Apresentamos exemplos de aventuras que podem ser criadas como ambiente; posteriormente discutimos os benefícios trazidos a professores e alunos ao criarem esses jogos. Estão entre esses benefícios um aprendizado mais eficiente, lúdico, dinâmico, participativo, descentralizado e autônomo. Também foi destacado que o Ambiente faz parte de um portal cooperativo, onde professores, alunos e demais interessados em jogos digitais e aprendizagem poderão interagir, criando outras Arquiteturas Pedagógicas.

Um teste de campo será realizado em breve, com alunos e professores do ensino básico, buscando identificar inadequações do sistema após o que iniciaremos um processo de aprimoramento. Futuramente será serão incorporadas novas funcionalidades tais como: editor de imagem e de animação, suporte a três dimensões e acessibilidade a pessoas com necessidades especiais.

\section{Referências}

Adventure Maker. Disponível em: <http://www.adventuremaker.com/>. Acesso em: 04 de abr. 2016.

Bomfoco, M. A. Os Jogos Eletrônicos e suas contribuições para a aprendizagem na visão de J. P. Gee. Revista Novas Tecnologias na Educação, v. 10, n. 3, dez. 2012.

Carmona, S. P. K; Carneiro, L. M. B. Game Engines e tradução intersemiótica: O insuflar de possibilidades criativas em estruturas estanques. IX SB Games: Trilhas de Games e Cultura. Nov. 2014.

Carvalho, A. A. A. et al. La Vouivre - Jogo da Glória. Atas do Encontro sobre Jogos e Mobile Learning. Coordenadoria Institucional de Educação a Distância, Universidade Federal de Alagoas, p. 382-399, 2012.

CARVALHO, M. J. S.; NEVADO, R. A.; MENEZES, C.S. Arquiteturas Pedagógicas para Educação a Distância: Concepções e Suporte Telemático, Simpósio de Informática na Educação, Juiz de Fora - MG, 2005.

Crawford, C. The Art of Computer Game Design. United States: McGraw-Hill, 1984.

Gee, J. P. Good Video Games and Good Learning. Phi Kappa Phi Forum, v.85, n.2, 2005

Griffiths M. The educational benefits of videogames. Education and Health, v.20, n. 3, p. 47-51, Reino Unido, 2002.

Lopes, N; Oliveira, I. Videojogos, Serious Games e Simuladores na Educação: usar, criar e modificar. Revista EFT - Educação, Formação e Tecnologias, v. 6, n. 1, jul. 2013.

Nunes, M; O’Neill, H. Fundamental de UML. 2 ${ }^{\text {a }}$ Edição. Lisboa: FCA - Editora de Informática, 204.

Prensky, M. Aprendizagem Baseada em Jogos Digitais. São Paulo: Editora Senac São Paulo, 2012.

Santos, O. L. et al. Mundos Virtuais para Construção de Arquiteturas Pedagógicas. VI Workshop de Arquiteturas Pedagógicas para Suporte à EAD mediada pela Internet. Anais do XXII SBIE - XVII WIE, Aracaju, nov. 2011. 